\title{
Special Issue on Surfaces Modification and Analysis for Innovative Biomaterials
}

\author{
Elvira De Giglio \\ Department of Chemistry, University of Bari “Aldo Moro”, 70126 Bari, Italy; elvira.degiglio@uniba.it; \\ Tel.: +39-080-544-2021
}

Received: 28 September 2020; Accepted: 17 November 2020; Published: 21 November 2020

\section{Introduction}

The reactivity of a biomaterial is literally "written on its surface", since it contacts host tissues and leads to the biological response. For this reason, when a biomaterial is designed, the physico-chemical features of its surface require special attention. Indeed, the surface of biomaterials, when properly tuned, elicit specific biological responses, leading to straightforward and predictable biomaterial integration.

Countless surface functionalizations could be performed, i.e., by means of chemical and electrochemical techniques, beyond modifications of surface topography and/or morphology. Each mentioned treatment requires careful study of the modified substrate. Hence, surface characterization techniques support biomaterial optimization, providing essential data to predict the in vitro and in vivo behavior of the biomaterial. Furthermore, in-depth studies of the biomaterials' surface assist in the monitoring of reproducibility, contamination, degradation, and stability, ultimately highlighting biomaterials' advantages and weaknesses.

This Special Issue presents recent developments regarding surface functionalization and biomaterial coatings. The reported strategies, applied to delivery systems or implantable devices, will provide useful clues for future research on innovative biomaterials.

\section{Surfaces Modification and Analysis for Innovative Biomaterials}

The Special Issue "Surfaces Modification and Analysis for Innovative Biomaterials" opened in June 2018 and closed in November 2019. During these months, seven manuscripts were published, i.e., five research articles and two systematic reviews. Each work describes the effectiveness of a surface modification from a particular point of view. A summary of the main achievements of the contributions in this Special Issue is reported below.

De Leo et al. proposed an innovative, gastroresistant delivery system, based on a polymeric-coated liposome formulation [1]. In their work, curcumin-loaded liposomes were coated with Eudragit to pass through the gastric environment without losing their cargo. Conversely, in an alkaline environment, such as the intestinal tract, the polymeric coating dissolves and the curcumin-loaded liposomes enter Caco- 2 cells to hinder oxidative stress.

Abdelgeliel and coworkers described antibacterial bioactive glasses through a particular surface functionalization [2]. Indeed, an antibacterial polyphenolic extract of the Egyptian algae Padina Pavonica was exploited both to coat the bioactive glasses and to reduce silver ions in situ, leading to silver nanoparticles. The functionalized bioactive glasses hampered the proliferation of Staphilococcus aureus, while ensuring the compatibility with bone progenitor cells.

The paper by McColgan-Bannon et al. dealt with the development of collagen grafting on force-spun membranes made of poly(3-hydroxybutyric acid-co-3-hydroxyvaleric acid) [3]. The functionalized membranes supported fibroblast adhesion and enhanced their metabolic activity, paving the way to the application of this biomaterial for dermal tissue regeneration. 
Wöltje and coworkers explored the genetic alteration of silkworms to obtain silk fibers functionalized with human platelet-derived growth factors [4]. The fibers were also modified with bioceramics and assembled into a 3D textile implant to achieve high levels of osteoconductivity. The developed biomaterial was highly cytocompatible, supported bone cell differentiation and resisted several cycles of load.

The goal of the paper by Cao et al. was the development of a polylactide-based, resorbable double coating on titanium implants, through micro-arc oxidation combined with dip coating [5]. The resorbable coatings, also with embedded antibiotics, showed adhesive properties on Ti-6Al-4V implants, being a promising substrate for bone reconstruction.

The review article authored by Sartori et al. analyzed current literature on strategies for implant osseointegration enhancement, focusing on osteoporotic bones [6]. Their survey highlighted that organic and inorganic films (i.e., ceramic coatings) promoted osseointegration in osteoporotic bones, but the main data were related to animal models. Conversely, clinical approaches did not refer to implant functionalization strategies, pointing out the need for further translational research.

Finally, Cometa et al. revised the electrochemical strategies used to coat titanium implants with smart polymeric films [7]. The described techniques allowed for a versatile functionalization of implantable materials, aimed at achieving bioinert or bioactive films. A critical discussion of the advantages and flaws of the most updated electrochemical approaches was provided.

\section{Perspectives}

The past decades have seen a substantial integration between scientists belonging to different research areas (i.e., engineers, chemists, biologists), aiming at designing multifunctional biomaterials, able to retain mechanical and physico-chemical features while developing a positive biological response. Significant improvements have been achieved in biomaterial surface functionalizations. This research topic is still growing, providing new opportunities to enhance implant performances with scalable and cost-effective approaches. Future works will develop new, intriguing solutions to shed light on biomaterials' interactions with host tissues, and finally bringing better devices to the biomedical market.

Acknowledgments: Maria A. Bonifacio is greatly acknowledged for her precious collaboration in the Coatings Special Issue management.

Conflicts of Interest: The authors declare no conflict of interest.

\section{References}

1. De Leo, V.; Di Gioia, S.; Milano, F.; Fini, P.; Comparelli, R.; Mancini, E.; Agostiano, A.; Conese, M.; Catucci, L. Eudragit S100 Entrapped Liposome for Curcumin Delivery: Anti-Oxidative Effect in Caco-2 Cells. Coatings 2020, 10, 114. [CrossRef]

2. Abdelgeliel, A.S.; Ferraris, S.; Cochis, A.; Vitalini, S.; Iriti, M.; Mohammed, H.; Kumar, A.; Cazzola, M.; Salem, W.M.; Verné, E.; et al. Surface Functionalization of Bioactive Glasses with Polyphenols from Padina pavonica Algae and In Situ Reduction of Silver Ions: Physico-Chemical Characterization and Biological Response. Coatings 2019, 9, 394. [CrossRef]

3. McColgan-Bannon, K.I.S.; Upson, S.; Gentile, P.; Tausif, M.; Russell, S.; Dalgarno, K.; Ferreira, A.M. Biomimetic Properties of Force-Spun PHBV Membranes Functionalised with Collagen as Substrates for Biomedical Application. Coatings 2019, 9, 350. [CrossRef]

4. Wöltje, M.; Brünler, R.; Böbel, M.; Ernst, S.; Neuss, S.; Aibibu, D.; Cherif, C. Functionalization of Silk Fibers by PDGF and Bioceramics for Bone Tissue Regeneration. Coatings 2020, 10, 8. [CrossRef]

5. Cao, X.Y.; Tian, N.; Dong, X.; Cheng, C.K. Implant Coating Manufactured by Micro-Arc Oxidation and Dip Coating in Resorbable Polylactide for Antimicrobial Applications in Orthopedics. Coatings 2019, 9, 284. [CrossRef] 
6. Sartori, M.; Maglio, M.; Tschon, M.; Nicoli Aldini, N.; Visani, A.; Fini, M. Functionalization of Ceramic Coatings for Enhancing Integration in Osteoporotic Bone: A Systematic Review. Coatings 2019, 9, 312. [CrossRef]

7. Cometa, S.; Bonifacio, M.A.; Mattioli-Belmonte, M.; Sabbatini, L.; De Giglio, E. Electrochemical Strategies for Titanium Implant Polymeric Coatings: The Why and How. Coatings 2019, 9, 268. [CrossRef]

Publisher's Note: MDPI stays neutral with regard to jurisdictional claims in published maps and institutional affiliations.

(C) 2020 by the author. Licensee MDPI, Basel, Switzerland. This article is an open access article distributed under the terms and conditions of the Creative Commons Attribution (CC BY) license (http://creativecommons.org/licenses/by/4.0/). 